\title{
Visual Analysis of Current Research Situation of Campus Football at Home and Abroad Based on Knowledge Map
}

\author{
Yuzhang Han \\ P.E. Dept. of San Da University \\ Pu Dong New Area, Shang Hai, China
}

\author{
Shufan Guo \\ Institute of Physical Education \&Health \\ Shang Hai Li Xin University of Accounting \& Finance \\ $\mathrm{Pu}$ Dong New Area, Shang Hai, China
}

\author{
Xing Wang \\ School of Physical Education and Training \\ Shanghai University of Sport \\ Yang Pu Area, Shang Hai, China
}

\begin{abstract}
By using Cite Metrics and Information Visual Citation Analysis software (CitespaceIII) to analyze 728research papers on campus football from CNKI database and 507papers from WOS database ranged from 1994 to 2014, the study tries to demonstrate the similarities and the differences of the hot spots of campus football research both home and abroad. The results show that overseas football research is more comprehensive and cross-permeable; more attention are paid to the students' health monitoring and the popularization of medical knowledge; while the researches in China focus more on the research of organization management and the interference factors and so on. In fact, the integration of football with education, health and safety consciousness of the students' participation in football is what we must be concerned about for the further development of football on campus in China
\end{abstract}

Keywords-campus football; knowledge map; status quo; visualization

\section{THE RESEARCH PURPOSE}

In recent years, with the popularization and development of campus football in China, a large number of scholars have conducted in-depth researches on campus football, which provides great theoretical support for the further development of campus football. However, most researches on campus football in China mainly focus on talents training modes, management systems and interference factors. However, there are few comparative studies on the status quo and the summary of campus football at home and abroad. The purpose of this paper is to use CitespaceIII software to visualize the status quo of campus football research both at home and abroad so as to get to know the similarities and differences of the campus football researches at home and abroad and to provide some references and significance for the research and practice of campus football in China.

\section{DATA SOURCES AND RESEARCH METHODS}

\section{A. Data Source}

CNKI and WOS database are used as data sources in the study. Chinese literature is based on the CNKI database. Foreign literature is based on Web of Science (TM) core collection of thesis database. The data source of the literature is shown as in Table I

TABLE I. THE DATA SOURCE LIST

\begin{tabular}{cll}
\hline & \multicolumn{2}{c}{ Contents } \\
\hline Data source & Data source CNKI & Web of Science(SCIE,SSCI,A\&HCI) \\
Search formula & Search formula theme(exact) & theme(exact) \\
Time span & Time span $1994 \sim 2014$, & $1994 \sim 2014$ \\
type & Type conference abstract, & Articles \\
result & result periodicals, dissertations & 507
\end{tabular}

\section{B. Research Method}

In this paper, information visual citation analysis software CitespaceIII is used to analyze the literature and the maps are

Funding: The research received grant from Shanghai University Sports Research Project (project No. HJTY-2016-D41) used to present the results of analysis, the network nodes are identified as institutions, authors, keywords, research institutes and so on. The default parameters are selected and the knowledge map is obtained after running. 
In view of the fact that the information visualization citation analysis software CitespaceIII still has some shortcomings in the processing of data information, this paper makes a thorough interpretation of the literature data combined with mathematical statistics and content analysis.

\section{Results and Analysis}

1) Analysis of the time characteristics of campus football at home and abroad

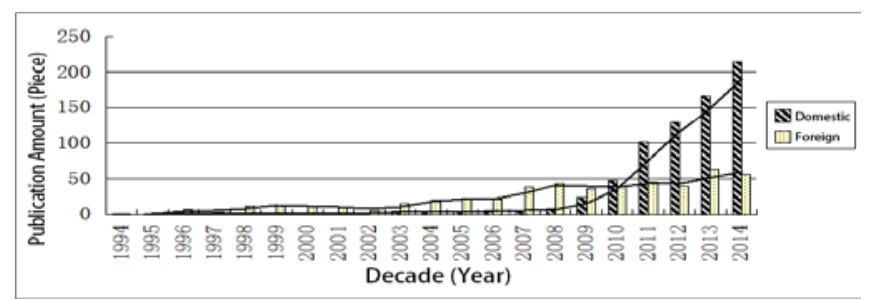

Fig. 1. Annual distribution of domestic and international volume distribution

Through the statistical analysis of the domestic and international annual publications in 1994 2014 years, we can see that the number of annual studies on campus football has increased over the past twenty years. According to the analysis of the trend of the image, it is found that the number of foreign documents has increased steadily, and the biggest increase of the domestic document volume appears in 2010. "The Central Committee and the State Council on strengthening the youth sports enhance youth physical view" ([2007]7) and the Ministry of education, the State Sports General Administration "on the national youth campus football activities of the notice" (group [2009]54) issued a dramatic increase in the amount of documents issued on the campus football influence.

From the time of writing, the study of campus football in China is relatively late compared with the study of foreign campus football. The development of campus football needs scientific research to guarantee. The research volume of campus football at home and abroad is developing rapidly, which shows that the attention of this field is increasing. In 2010, the amount of domestic service is beyond the foreign countries, but the development of the actual campus football is far less than that of the foreign countries. The number of policy documents issued by the State Council, the Ministry of education and the State Sports General Administration is positively correlated with the number of research on campus football. The attention of the government and management department has increased the research enthusiasm of campus football. As a record high in 2014, largely in October 2014, the State Council issued the "State Council on accelerating the development of the sports industry to promote a number of opinions" sports consumption has a great relationship, emphasis on promoting the campus football in the opinion, the development of youth football will rise to the national strategic level, research on campus football has become more and more important.

\section{2) Research field analysis}

According to CNKI's disciplinary classification, there are 10 academic fields on China's campus football research, which mainly distributed in sports(78.43\%) and education (21.16\%),the two fields account for (99.59\%) of the 728 articles, and papers on biology, news \&communication and special medicine only account for $0.41 \%$.

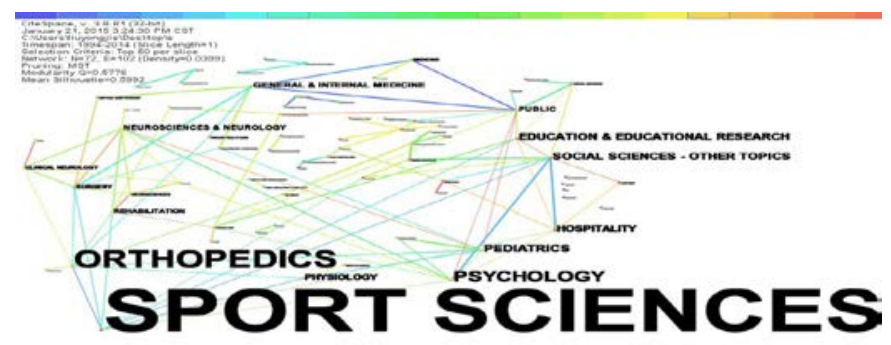

Fig. 2. Distribution of foreign campus football disciplines

Fig. 2 shows that the research field of foreign campus football abroad is extensive in the past 1994-2014 years, and the cooperation between various fields is intensive. The research takes SPORT SCIENCES (Sports Science), PSYCHOLOGY (Psychology) and ORTHOPEDICS (Department of orthopedics) as the main disciplines. Thus, the research focus on the campus football sports health abroad in the course of the study, the changes of physiological indices of attention the students participate in the campus football process, the medical research combined with the campus football research, is conducive to the healthy growth of young students so as to ensure the sustainable development of the campus football. At the same time, it also indicates that the research of campus football in other countries is interpenetrating in social science research and Natural Science (medicine, psychology and so on), so as to promote the comprehensiveness of campus football research and achieve results in the actual development of campus football

Comparison of the overall distribution of Chinese and foreign campus football studies show a sharp contrast, Chinese focuses on policy review research, interdisciplinary relationship is relatively weak; and abroad tend to health research campus football, interdisciplinary contact more closely, it is also for the future research of our school football offers enlightenment, multi-disciplinary integration the combination of basis and application.

\section{3) Research organization analysis}

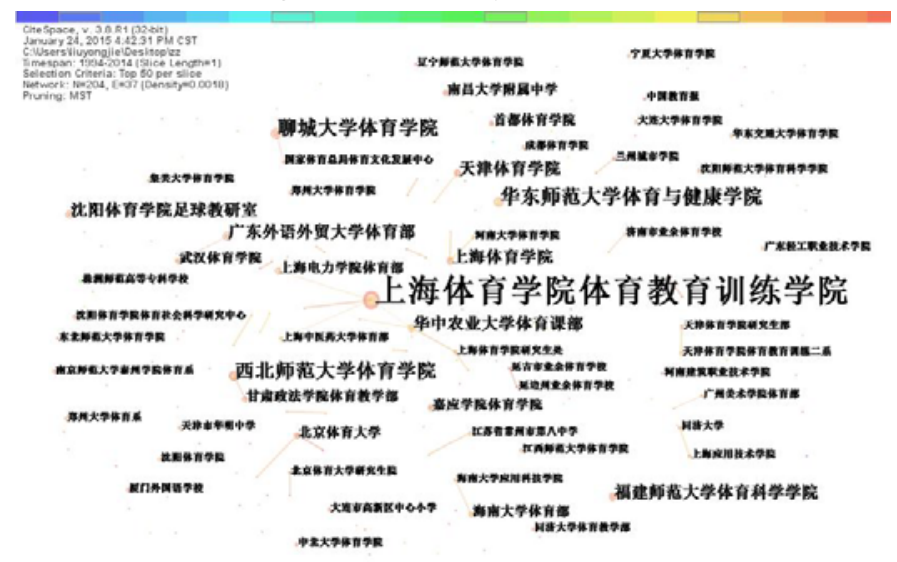

Fig. 3. Distribution map of Chinese campus football research institutions 
From Fig. 3, we know that there are many research institutions on campus football in China, and the cooperation among various institutions is less. To retrieve data from the literature that the number ranked in the top ten research institutions are the Institute of physical education training in Shanghai Institute of Physical Education (confirmed by Shanghai Institute of Physical Education and the same institution), East China Normal University School of physical education and health of Liao Cheng University Sports Institute, Northwest Normal University Sports Institute, Guang Dong University of Foreign Studies, Shanghai Institute of Physical Education, Department of Physical Education and Sports Science Institute of Fujian Normal University, Department of Physical Education, Hua Zhong Agricultural University Shen Yang Sport University football department, Tian Jin University of Sport. According to the number of the research institutions engaged in the research of the campus football in China is mainly sports colleges and normal universities, carry out the campus football managers, teachers and other personnel mainly by the referee, sports colleges and universities and normal colleges of transportation, to a certain extent determines the distribution of high institutions.

The research shows that the college football research institutions in China are in a discrete state, and the cooperation between the research institutions depends on the geographical location and the close cooperation. Among them, there is a relatively close cooperation relationship between Shanghai Institute of Physical Education sports education and Training Institute and Shanghai University of Electric Power sports department, Shanghai University of Traditional Chinese Medicine sports department and so on, and the Liao Cheng University Sports Institute has a cooperative relationship with the State Sports General Administration sports culture development center. The research found that in Shanghai and the National Football League campus related organization and training to carry out the implementation of inter subjectivity basically are from these institutions, involved a lot of the campus football organization and management work of the campus football research attention will naturally appear convex.

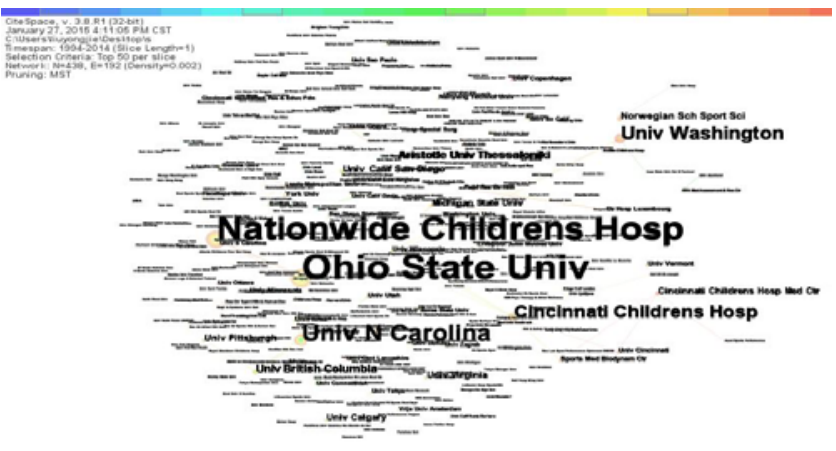

Fig. 4. Distribution map of foreign campus football research institutions

There are a large number of research institutions in foreign campus football, but the cooperative relationship between the research institutions has not been clearly presented in Fig. 4. In the study of campus football in various countries and regions, Study on the mechanism of the contribution of the
United States is more prominent, such as NATIONWIND CHILDRENS HOSP (National Children's Hospital), OHIO STATE UNIV (Ohio State University), UNIV N CAROLINA (University of North Carolina-Chapel Hill) and other research institutions have close cooperation with other research institutions. Among them, NATIONWIND CHILDRENS HOSP (National Children's Hospital) as a high-yielding research organization and has frequent cooperation with other school football research institutions, thus promoting the development of medical field and campus football integration research. Therefore, the school football research institutes in the US are representative. It is necessary for us to do some research on these research institutions.

\section{4) Research hot spots and frontier analysis}

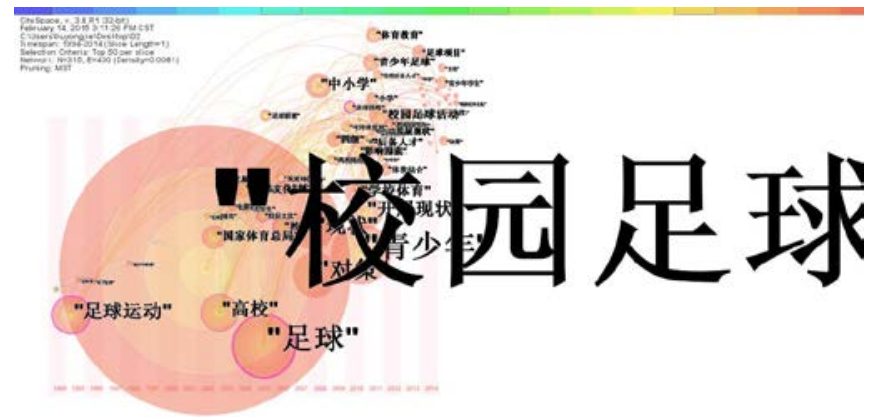

Fig. 5. Distributions Atlas of hot spot time zone in campus football research in China

Since 2000, the campus football research heat rising, the overall trend of discovery research, our research focus from the university campus football soccer, football league, the campus football development of the status quo to youth football, the campus football development and promotion strategy, the campus football teaching and training and other aspects of deepening transfer. The word "football", "talent", "the four level" campus football by national and local attention, showing the campus football in Shanghai, Guangzhou and other areas of the layout of primary school, junior high school, high school and university level Four one-stop soccer talent training mode. To achieve long-term development of football, we need to learn from the advanced experience of football power, and establish and perfect the training path of reserve talents from the training of young football talents. ${ }^{[1]}$ It is more conducive to the development of campus football in China, and more effectively draw lessons from overseas training mode of campus football reserve talents, and further improve our school football talents training mechanism.

To achieve the dream of football, Chinese football must first grasp the youth football, expand the football population, carry out campus football activities, let sports return to education, and make sports play an important role in the education system. Secondly, improve the Youth Football League, an important role in understanding campus football competition system; construction of four level system of primary school, junior high school, high school, university campus, attention League interscholastic League should be carried out in different groups according to the level of the team; competition game should be the organic combination of focus and U series, and different competition venues age can be 
adjusted; perfect competition management system, emphasizing the health, happiness and fair competition experience. Finally, we should improve the management of young football talents, improve the channels for the growth of young soccer, and take the training mode of primary school, middle school and University as a main line, and focus on training ways. Under the current education system, based on the primary school, we should implement the policy of supporting campus football, improve the level of football majors, and enact the policy of examination and enrollment to attract talented students, so as to encourage students to learn and train well. The road of football development with Chinese characteristics has been formed

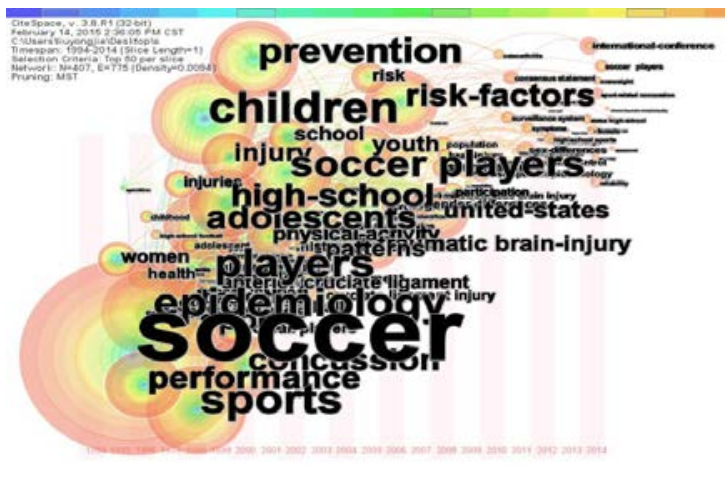

Fig. 6. distribution map of hot spot zone in foreign campus football research

Fig. 6 shows that the research on soccer in foreign countries has been highlighted in 1994-2004 years' research hotspots, including football, soccer players selection, training and physical education. The research direction has changed in 2004-2014 years. It has carried out multi angle and multi-level research in school physical education, sports injury prevention and recovery methods, physiological changes in different gender and training.

Analysis of 1994-2014 years of foreign campus football related research, with the passage of time, research into other fields of discipline. "Epidemiology ", "risk-factors" and "sportinjuries" and other medical terms have been widely mentioned. It shows that in the development of campus football in foreign countries, the physical health of students is particularly emphasized. For example, the factors of knee injury, the factors of head injury, how to reasonably carry out football and other aspects of age and gender are widely applied to the research of campus football by using medical knowledge and means. Interpretation of the literature finds that experimental methods have been widely used in the study, and provide strong support for campus football research by using kinematic indicators and physiological indicators of scientific instruments.

\section{5) Analysis of high cited literature}

By analyzing the high - cited foreign language, foreign research focuses on the influence of football on human health, and the experimental method is used more in the study. In the research of campus football, it shows that the prospective evaluation of neuromuscular training has a significant protective effect on the knee joints of male and female athletes. Among male athletes, the training effect is more obvious than that of female athletes because of muscle strength. ${ }^{[2]}$ Due to the related research on human health has been a large number of foreign researchers, the traumatic brain injury in sports research involving sports injury in (concussion mainly) after the incidence of traffic accidents (15-24) years old in the national citizens), football is a traumatic brain injury incidence rate of sports the highest ${ }^{[3]}$. Experts and physical experts analyzed the risk factors of knee joint and ankle joints in the sports injury risk. The muscle strength of leg type and lower extremity joint played a leading role. The injuries of ankle joints and anterior cruciate ligament injuries of the knee joints were not significant in football games.

\section{CONCLUSIONS AND SUGGESTIONS}

\section{A. Conclusions}

1) external features: with the campus football research heat rise, the overall volume of papers at home and abroad showed a rising trend; the distribution of Chinese and foreign campus football studies show a sharp contrast, Chinese focuses on policy review research, interdisciplinary relationship is relatively weak; and foreign to the application of partial health campus football, interdisciplinary closely; foreign campus football research institutions of many colleges and universities, our country mainly in the normal professional colleges, to narrow, lack of fusion penetration; foreign to the United States as the lead, cross penetration highlights, research institutes active in medical institutions, frequent exchanges and integration.

2) Internal characteristics: our school football research is limited to review policy research, which is mainly reflected in the talent training mode, management system, competition system and hindrance factors in campus football, and there is a lack of application research. The study of campus football abroad absorb students' physical health monitoring and medical knowledge, broaden the research dimension of football on campus, reflecting the campus football to the students "health first" thought, it also highlights the research on campus football in China in the aspects of the shortcomings and deficiencies of revelation in the future research should not be neglected in the campus football or to avoid difficulties.

\section{B. Proposal}

In the background of campus football reform, through the policy advantage, do the basic theory research and practical application of the fusion, referring to foreign experience, the campus football into the educational environment, clear youth fitness and health in our country and improve the popularity of the campus football goal based on the new path for China to explore the development of campus football the construction of the campus football, enhance the management and safeguard system of football talents, promote the healthy growth of young students comprehensively.

\section{REFERENCES}

[1] Haiyuan Liu. Research on the development of competitive sports in Chinese universities [D]. Beijing Sport University, 2003 
[2] State General Administration of physical education, Ministry of education. Circular on the development of the national campus football activities [S]. Body group character [2009] 54

[3] Weidong,Li Zhang Tingan, Lu Yu. The investigation and analysis of the national youth campus football activities [J]. Journal of Shanghai Institute of Physical Education, 2011,35 (5): 22-25
[4] Wangge,PresentSituationandProblemsinCampusSoccerActivitiesandCou ntermeasures[J]. ournalofShenyangSportUniversity,2011,30(2):99-102

[5] Helmut M. Dietland egon franck. Governance failure and financial crisisin GermanFootball[J].Journal of Sports Economics,2007(12):664665. 